\title{
Closed-Loop Utilization of Molten Salts in Layered Material Preparation for Lithium-Ion Batteries
}

\author{
Zhanjun Chen ${ }^{1,2+}$, Tao Wang ${ }^{1,3 \dagger}$, Haijun $\mathrm{Yu}^{4}$, Jun Guo ${ }^{2}$, Hongbin $\mathrm{Zhong}^{2}$, Chuanyue $\mathrm{Hu}^{2}$, \\ Ruirui Zhao ${ }^{1 *}$ and Hongyu Chen ${ }^{1 *}$ \\ ${ }^{1}$ School of Chemistry, Engineering Research Center of MTEES (Ministry of Education), South China Normal University, \\ Guangdong, Guangzhou, China, ${ }^{2}$ Hunan Provincial Key Laboratory of Fine Ceramics and Powder Materials, School of Materials \\ and Environmental Engineering, Hunan University of Humanities, Science and Technology, Loudi, Hunan, China, ${ }^{3}$ School of \\ Materials Science and Engineering, Dongguan University of Technology, Dongguan, Guangdong, China, ${ }^{4}$ Guangdong Brunp \\ Recycling Technology Co., Ltd., Foshan, Guangdong, China
}

Molten-salt assisted solid-state synthesis is considered a promising method in obtaining layer-structured cathodes for lithium-ion batteries with homogeneous elemental distribution and controllable morphologies. However, drawbacks like resource wasting which have arisen from redundant salt removal after sintering greatly hinder the broader application of this technique. In this paper, a closed-loop utilization of molten salts is proposed for the first time with specific electrochemical properties of the products studied. Results confirm the feasibility of this strategy, and that with only replenishing $\mathrm{LiOH}$, the recycled $\mathrm{LiOH}-\mathrm{LiCl}$ molten salts can be successfully reused into another $\mathrm{LiNi}_{0.5} \mathrm{Co}_{0.2} \mathrm{Mn}_{0.3} \mathrm{O}_{2}$ synthesis, which exhibits almost equal electrochemical performance to the product using fresh molten salts. We believe this research can provide significant insight in guiding green and environmentalfriendly preparation methods involving molten salts.

Keywords: molten salts, layered materials, closed-loop, lithium ion batteries, recycling

\section{INTRODUCTION}

Layered materials with a typical formula of $\mathrm{LiMeO}_{2}(\mathrm{Me}=\mathrm{Ni}, \mathrm{Co}, \mathrm{Mn}$, etc. $)$ are arising significant concerns as lithium-ion battery (LIB) cathodes nowadays due to their high energy density, superior rate and cycling performance, which are essential factors to satisfy emerging application fields like portable electronic devices, and electric vehicles (EV) (Wang et al., 2018; Bianchini et al., 2019; Lee et al., 2019; Liu et al., 2020). Various methods have been developed in synthesizing layered materials, while the commonly accepted route is employing liquid-based techniques (co-precipitation, sol-gel, hydrothermal) to prepare precursors (transition metal hydroxides, or carbonates), followed by the long-time solid-state sintering of the mixed precursor and lithium source to obtain the final products (Sari and Li, 2019; Xu et al., 2020; Zhao et al., 2020). In this process, solid-state sintering factors should be paid care and attention to since incorrect parameters often brings uneven elemental distribution along with unwanted impurities in the target materials (Jr et al., 2011; Bianchini et al., 2020).

As a typical method in ceramic powder preparation, molten-salt assisted solid-state synthesis is also extensively employed in making cathode/anode materials for LIBs, which is suggested as being useful in obtaining a homogenous single phase of layered-structured materials due to the solution nature of the molten salts under high temperature: the resultant liquid-phase sintering enables controllable microstructure via tuned parameters, while the processing cost is simultaneously reduced since the needed reaction temperature is relatively low in molten-salt assisted synthesis 
compared with conversional solid-state method. A series of layered materials, including $\mathrm{LiCoO}_{2}$, ternary layered materials, Li-rich materials, are successfully prepared via this technique in previous papers (Chang et al., 2008; Wang et al., 2014; Li et al., 2017; Zhu and Chen, 2019). Moreover, compared with single molten salt, the salts' eutectic mixture is more preferred in layered material synthesis due to their lowered melting points. During the molten salt synthesis, the mixture involving molten-salts and reactants is heated to a temperature above the melting point of the eutectic mixture, when the melted salts act as a solvent during the particle growth process (Kimura, 2011). This solution-based sintering can boost the reaction rate of the reactants, thus lower the reaction temperature and increase the homogeneous distribution of constituent elements, resulting in controllable particle sizes as well as particle shapes of the final products (He et al., 2015; FTsalt-Fact Salt Phase Diagrams).

Even products with excellent properties the molten salt synthesis can provide, however, the inevitable waste of chemical raw materials (the molten salts) from the waterwashing step, which is usually applied after sintering to remove the redundant salts, still hinder its broader application. However, there is scarce literature available focus on reusing the molten salts based on our knowledge, since compared with the cheap nature of employed molten salts, recovering, separating, and purifying the molten salts to industrial-grade reagents seems more energy-consuming and time-wasting if traditional hydrometallurgical recovery is followed.

In this contribution, we aimed to develop a simple and effective method in realizing a close-loop utilization of the molten salts to synthesize ternary layered cathode for LIBs, and $\mathrm{LiOH}-\mathrm{LiCl}$ is employed as a prototype. This method is based on the observation that after molten-salt assisted solidstate sintering, the mole ratio of washed $\mathrm{LiCl}$ is nearly the same with its raw state, while the amount of $\mathrm{LiOH}$ decreased rapidly. By replenishing only $\mathrm{LiOH}$, the mixture can be re-employed as molten salts during the next synthesis, this method is quite facile and repeatable, as proven in this research, which can be also expanded to other kinds of layered materials and molten salts. We believe that this investigation will provide useful guidance in obtaining layered materials by using green and chemical-saving molten salt synthesis.

\section{EXPERIMENTAL PARTS}

\section{Material Synthesis}

The $\mathrm{LiNi}_{0.5} \mathrm{Co}_{0.2} \mathrm{Mn}_{0.3} \mathrm{O}_{2}$ (NCM) materials were synthesized using a molten salt assisted solid-state method. In detail, commercial $\mathrm{Ni}_{0.5} \mathrm{Co}_{0.2} \mathrm{Mn}_{0.3}(\mathrm{OH})_{2}$ precursor (Hunan brunp recycling science and technology co., ltd., China), $\mathrm{LiOH} \cdot \mathrm{H}_{2} \mathrm{O}$ (Aladdin, 98\%) and $\mathrm{LiCl}$ (Aladdin, 98\%) were mixed together and grinded evenly. The molar ratio of $\mathrm{Li}: \mathrm{Ni}_{0.5} \mathrm{Co}_{0.2} \mathrm{Mn}_{0.3}$ was controlled at 5:1, in which the molar ratio of $\mathrm{LiOH}: \mathrm{LiCl}$ was 0.63:0.37. The resultant mixture was subjected a heat-treatment at $300^{\circ} \mathrm{C}$ for $2 \mathrm{~h}$, followed by another heat-treatment at $850^{\circ} \mathrm{C}$ for $6 \mathrm{~h}$ in the presence of oxygen. The mixture was washed by deionized water several times and then separated by centrifuge. The solid powder was collected, dried, and then subjected to another sintering under oxygen atmosphere at $850^{\circ} \mathrm{C}$ for $2 \mathrm{~h}$ to obtain the layered products (named as NCM-P), while the washed filtrate was also collected for further salt recycling.

\section{DETERMINING THE CONCENTRATION OF LICL AND LIOH}

The concentration of $\mathrm{LiCl}$ and $\mathrm{LiOH}$ in the filtrate was determined by titrimetric analysis. Generally, the filtrate was divided into two parts to determine the concentration of $\mathrm{LiCl}$ and $\mathrm{LiOH}$ respectively. On the one hand, standard-concentrated $\mathrm{HCl}$ was used to determine the total alkalinity in the filtrate and thus obtain the amount of $\mathrm{LiOH}$, and methyl red-bromocresol green solution was used as an indicator. On the other hand, the amount of $\mathrm{Cl}^{-}$was calculated by using standard-concentrated $\mathrm{AgNO}_{3}$ solution while potassium chromate as indicator, the influence of $\mathrm{OH}^{-}$on $\mathrm{Cl}^{-}$was excluded using the equation of $\mathrm{OH}^{-}+2 \mathrm{Ag}^{+} \rightarrow \mathrm{Ag}_{2} \mathrm{O} \downarrow$.

\section{Recycling the Molten Salts}

The filtrate was evaporated until white-colored powders observed, and the obtained powder were collected after totally dried. The obtained powders were mainly comprised of $\mathrm{LiCl}$ and $\mathrm{LiOH}$ and the detailed contents of the $\mathrm{LiCl}$ and $\mathrm{LiOH}$ were determined by titrimetric analysis using the same method after re-dissolving the recycled powder into distilled water.

\section{Synthesis of NCM-1, NCM-2 and NCM-5}

Based on the titrimetric analysis results, a certain amount of $\mathrm{LiOH}$ was added to the recycled powders, reaching a molar ratio of $\mathrm{LiOH}: \mathrm{LiCl}$ equals to $0.63: 0.37$. The adjusted lithium salts were re-employed as molten salts and mixed with commercial $\mathrm{Ni}_{0.5} \mathrm{Co}_{0.2} \mathrm{Mn}_{0.3}(\mathrm{OH})_{2}$ precursor. The NCM material sintered by using regenerated $\mathrm{LiOH}-\mathrm{LiCl}$ from NCM-P was named as NCM-1, while NCM-2 was obtained by using the recycled molted salts recycled from NCM-1, and so on.

\section{Material Characterization}

$\mathrm{X}$-ray powder diffraction (XRD) patterns were recorded using a Bruker D8 advance diffractometer with $\mathrm{Cu}-\mathrm{Ka}$ source $(\lambda=$ $1.54056 \AA$ ) from $10^{\circ}$ to $90^{\circ}$ with a step size of $0.02^{\circ} \mathrm{s}^{-1}$. A scanning electron microscope (SEM) was taken on a PhilipXL30 instrument. For performing the temperature-dependent $\mathrm{XRD}$, the mixture involving molten salts and precursor, same to the reactants during sintering, was used as raw material, which was positioned in a silicon carbide tube in the furnace. The mixture was heated from $\mathrm{RT}$ to $800^{\circ} \mathrm{C}$ with a rapid heating $\left(20^{\circ} \mathrm{C} /\right.$ min), while XRD patterns were collected every $100^{\circ} \mathrm{C}$.

\section{Electrochemical Measurement}

Electrochemical testing was performed on 2025-type coin cells, with NCM as cathodic active materials and metallic lithium foils as counter electrodes. The active materials, polyvinylidene fluoride (PVDF) and acetylene black carbon (AB) were mixed with a mass ratio of 8:1:1 in making cathode, NMP was employed 

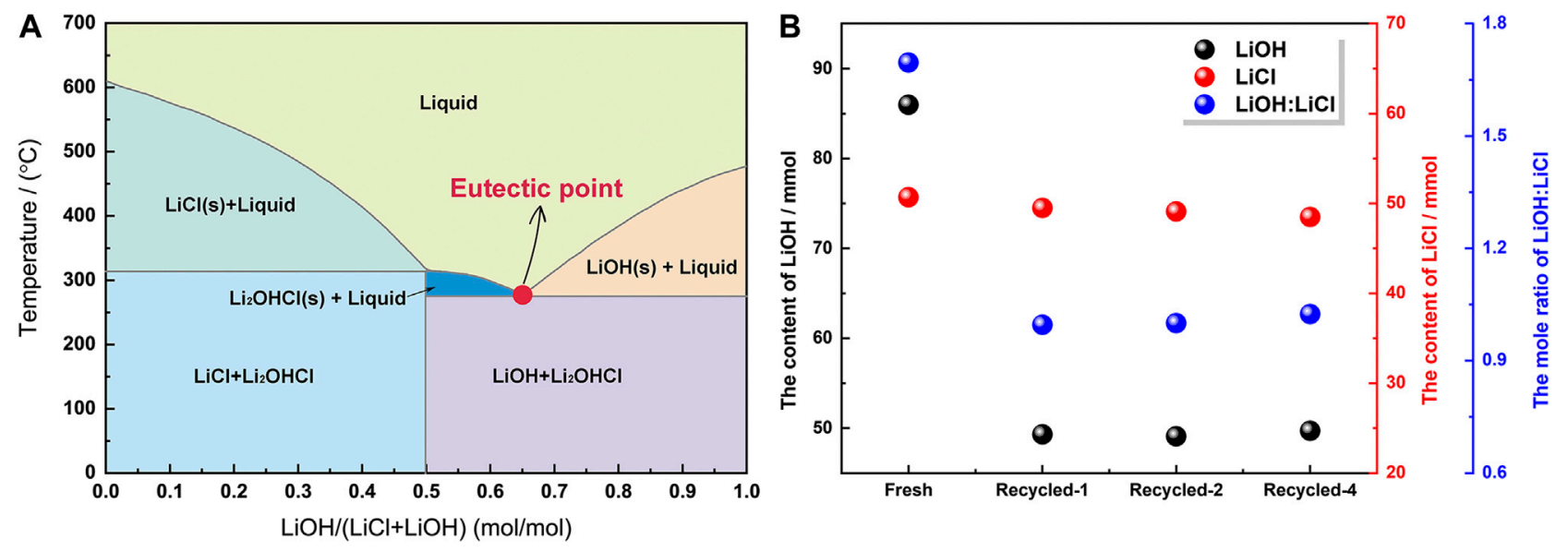

C

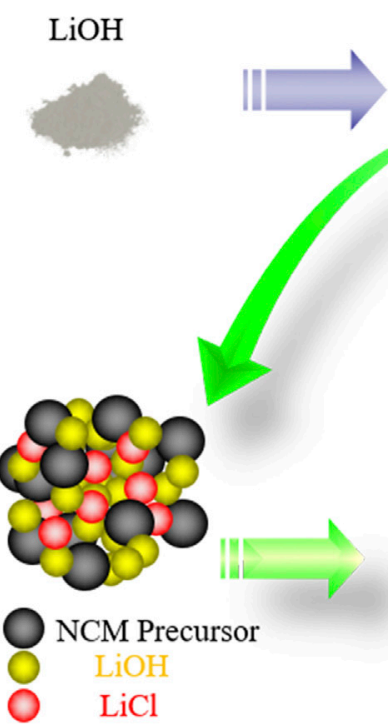

Mixing

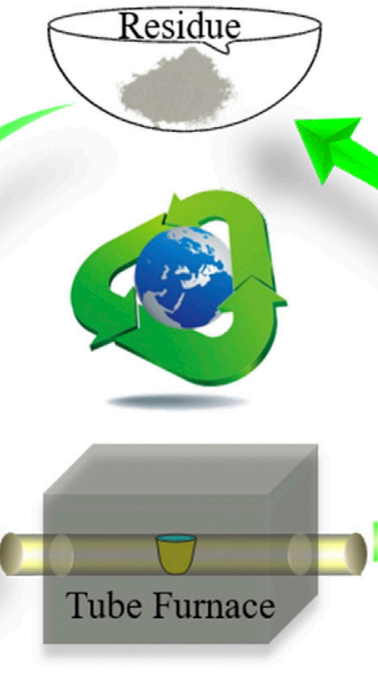

Sintering

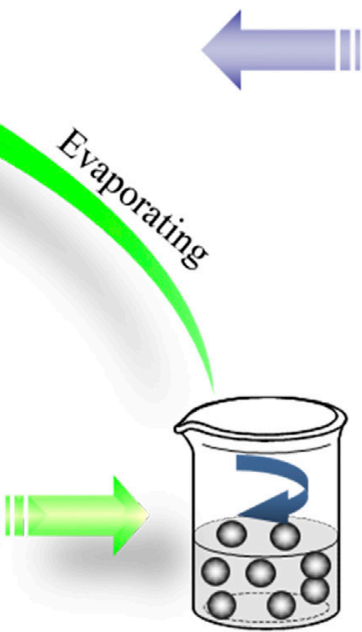

Washing
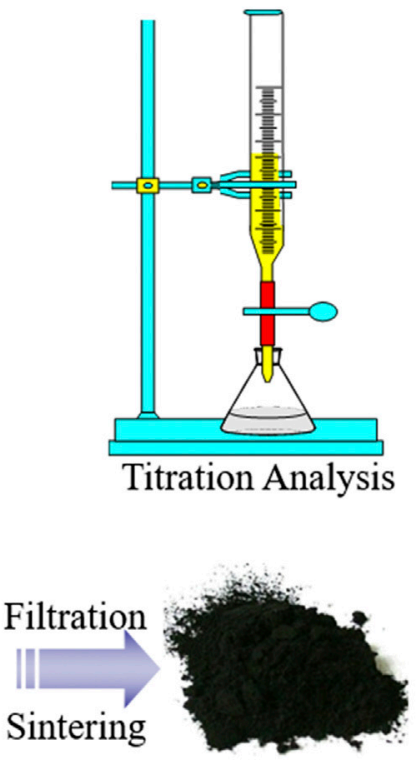

NCM Products

FIGURE 1 | (A) Phase diagram of LiOH and LiCl (reproduced from FACT salt database) (Bianchini et al., 2019). (B). the amount of substances (LiOH, LiCl) and the calculated mole ratio of $\mathrm{LiOH}: \mathrm{LiCl}$ in the fresh molten salts and water-washed solutions from NCM materials, which were determined by titrimetric analysis. A nomenclature of Recycled- $n(n=1,2,3 \ldots$. . is used to differentiate the solutions, while Recycled-1 is the solution from NCM-P, Recycled-2 from NCM-1, and so on. (C). Schematic illustration of "closed-loop utilization of molten salts" process during NCM synthesis.

as the solvent and a slurry was formed after grinding evenly; the slurry was coated onto an $\mathrm{Al}$ foil and dried at $100^{\circ} \mathrm{C}$ for $24 \mathrm{~h}$ under vacuum. $1 \mathrm{M} \mathrm{LiPF}_{6}$ in 3:7 (volume ratio) mixture of ethylene carbonate (EC) and dimethyl carbonate (DMC) was employed as electrolyte. The assembled coin cells were charge/discharged in the voltage range of $3.0-4.3 \mathrm{~V}$ on the CT2001A cell testing instrument (Land electronic co.) under different current densities. Electrochemical impedance spectroscopy (EIS) was performed on an Autolab potentiostat (PGSTAT302N, IECO CHEMIE B.V.), while the impedance spectra were recorded under a $0.02 \mathrm{~V}$ amplitude and a frequency range of $50 \mathrm{mHz} \sim$ $10^{5} \mathrm{~Hz}$.

\section{RESULTS AND DISCUSSIONS}

Our approach is based on the fact that when a eutectic solution of molten salts is employed, the needed optimal temperature in obtaining cathodes is not high enough to decompose all the molten salts. Herein, the $\mathrm{LiOH}-\mathrm{LiCl}$ mixture is studied as an example. According to their phase diagram (Figure 1A), when the mixture is composed of $\mathrm{LiOH}$ and $\mathrm{LiCl}$ at a molar ratio of $0.63: 0.37$, its melting point reaches as low as around $275^{\circ} \mathrm{C}$; thus the $0.63 \mathrm{LiOH}-0.37 \mathrm{LiCl}$ eutectic system is employed as molten salts in sintering all the NCM materials in the current research. 

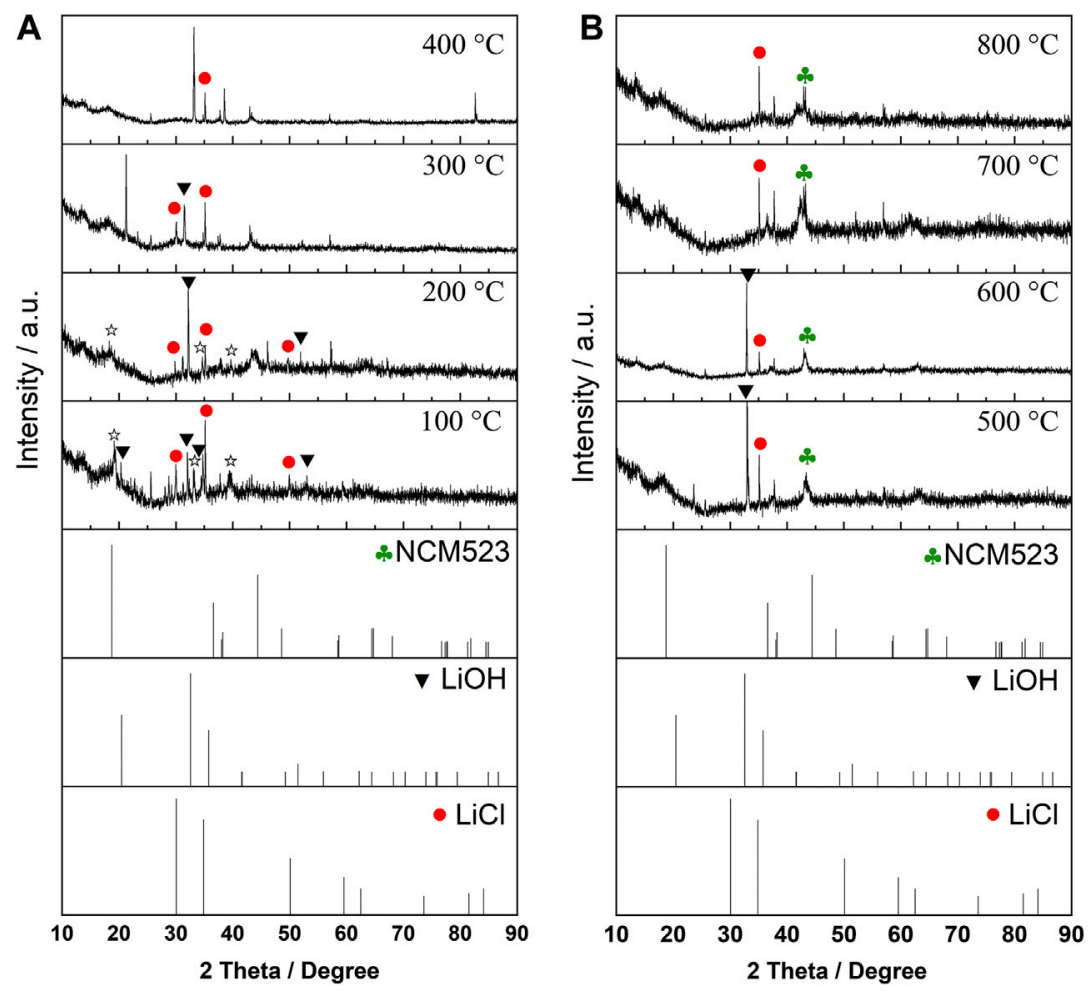

FIGURE 2 | Temperature-dependent XRD patterns measured upon heating of lithium and precursor mixture in a temperature range from $100^{\circ} \mathrm{C}$ to $800^{\circ} \mathrm{C}$.

Titrimetric analysis was first carried out to determine the components in the fresh and water-washed solution containing molten salts. Following the description as listed in the experimental part, the analysis was performed three times for each sample, while the average value is plotted in Figure 1B. It's observed that compared with fresh molten salts, which is mixed by commercial $\mathrm{LiOH}$ and $\mathrm{LiCl}$, the recycled mixture exhibits a similar content of $\mathrm{LiCl} \quad\left(\mathrm{Cl}^{-}\right) \quad(48.5-49.5 \mathrm{mmol}$ against $50.7 \mathrm{mmol}$ ), on the contrary, the content of $\mathrm{LiOH}$ is decreased rapidly from $86.0 \mathrm{mmol}$ to $49.1-49.7 \mathrm{mmol}$, which means almost one-half $\mathrm{LiOH}$ is lost during the sintering process. XRD results for fresh and recycled molten salts further confirm this result: the fresh salt exhibits a mixed phase of $\mathrm{LiCl}$ and $\mathrm{LiOH}$, while the recycled one is dominated by $\mathrm{LiCl}$ combined with trace possibly multi-anionic salt, i.e. $\mathrm{Li}_{2} \mathrm{OHCl}$ (Hood et al., 2016).

Inspired by these results, we tried to replenish only $\mathrm{LiOH}$ to the recovered products to make a $0.63 \mathrm{LiOH}-0.37 \mathrm{LiCl}$ eutectic system again, which was served as molten salts during the preparation of NCM-1 NCM-5 materials. We named this process as closed-loop utilization of molten salts, and schematic illustrating it into Figure 1C. Generally, commercial lithium salts were used for synthesizing NCM-P, while recycled salts, composed of evaporated solute and newly added $\mathrm{LiOH}$, were used in preparing NCM-n $(n=1,2$, and 5) materials. In the following parts, we will focus on proving the feasibility of this method.

To gain more insights into the chemical processes occurring during the material synthesis with the help of molten salts as well as the structural evolution, temperature dependent XRD patterns were performed and collected on the lithium and precursor mixture in a wide temperature range from $100^{\circ} \mathrm{C}$ to $800^{\circ} \mathrm{C}$. As shown in Figure 2, although the data quality based on laboratory diffractometers is insufficient for whole-pattern refinement, (Moorhous et al., 2016), we can still find some useful results based on a rough analysis. A multiphase comprised by $\mathrm{LiOH}$, $\mathrm{LiCl}$, and oxide precursor can be detected under low temperature ranges, intermediate phases like $\mathrm{Li}_{2} \mathrm{OHCl}$ can be observed with the temperature increasing. The layered phase can be found at a temperature of $c a .500^{\circ} \mathrm{C}$ as expected with broad scattering peak, possible because of the rapid heating along with XRD testing proceeding. Interestingly, the characteristic peaks belong to $\mathrm{LiOH}$ are already disappeared above $600^{\circ} \mathrm{C}$, while the $\mathrm{LiCl}$ can also be detected in the mixture. This observation agrees well with our hypothesis and provides an explanation for the titrimetric analysis results. Based on the above analysis, it can be inferred that the $\mathrm{Cl}^{-}$is stayed in the salt flux under high temperature, either in the form of $\mathrm{LiCl}$ or $\mathrm{Li}_{2} \mathrm{OHCl}$, while the $\mathrm{LiOH}$ was decomposed, possibly into $\mathrm{Li}_{2} \mathrm{O}$ and $\mathrm{H}_{2} \mathrm{O}$ based on pervious literature (Kudo, 1979). However, more investigations are needed in making the whole process clear in the future.

The structural and morphological information of the obtained NCMs by using different molten salts was collected and shown in Figure 3. Both the received samples, either synthesizing from fresh molten salts or recycled ones, exhibit a typical pattern of $\alpha-\mathrm{NaFeO}_{2}$ with $\mathrm{R} \overline{3} m$ space group, no diffraction peaks belong to impurities were found in these samples. Besides, the two coupled 

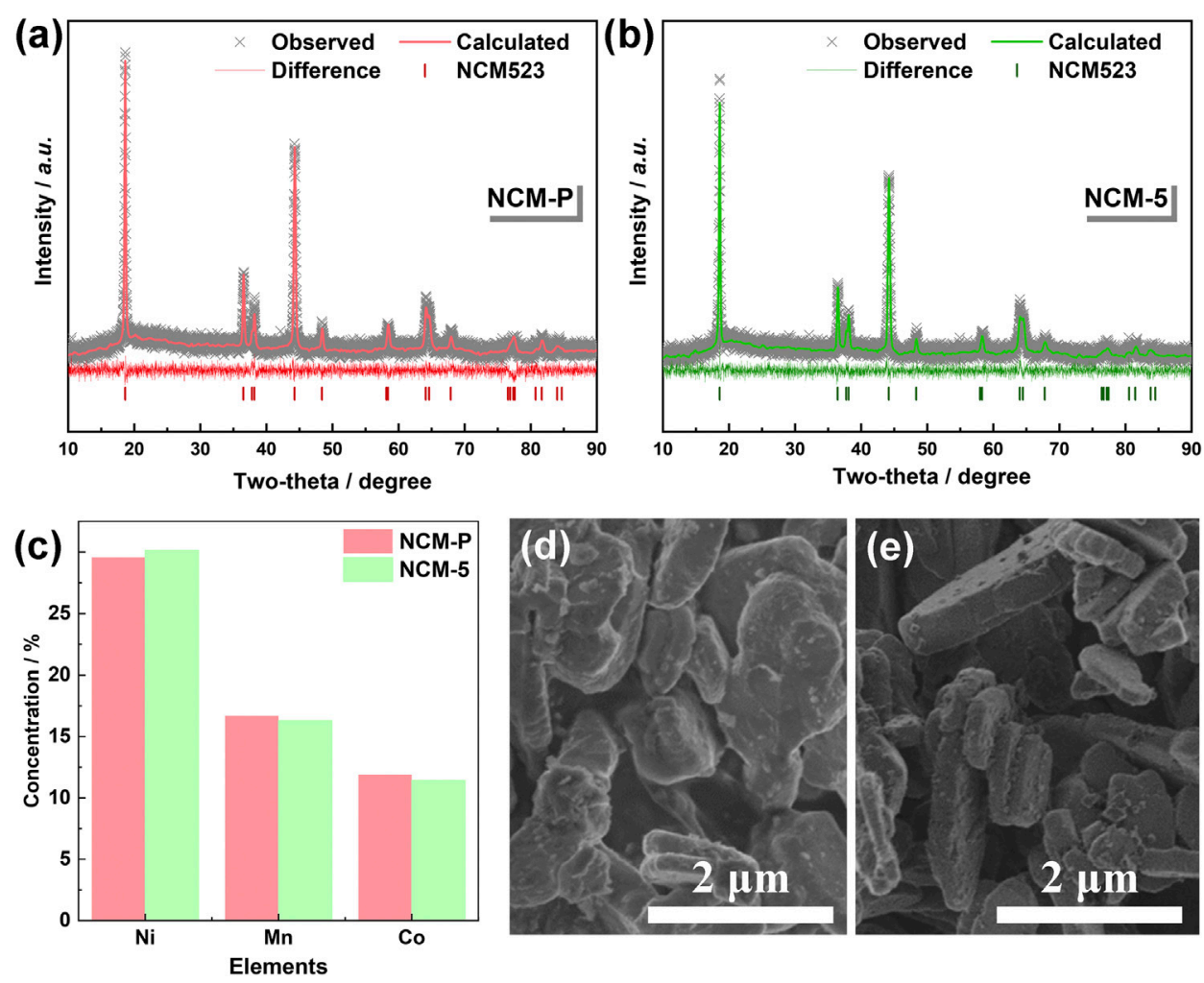

FIGURE 3 | Structural and morphological characters of NCM-P and NCM-5 samples. XRD patterns for NCM-P (A) and NCM-5 (B), ICP results for NCM-P and NCM-5, and the SEM images for NCM-P (D) and NCM-5 (E).

peaks $(006) /(012)$ and $(108) /(110)$ are well-spilt in all the products, indicates a well-developed hexagonal structure. All samples exhibit similar $\mathrm{I}_{(003)} / \mathrm{I}_{(104)}$ ratio higher than 1.5 , (Dahn et al., 1990; Ohzuku et al., 1993), and identical $\left.\mathrm{I}_{(006)}+\mathrm{I}_{(102)}\right) / \mathrm{I}_{(101)}$ ratio lower than 0.5 , meaning that the powders exhibit similar small cation mixing in their layered structure. Further results from ICP (Figure 3C) show that the elemental concentration in various samples is slightly changed, which is consistent with their slightly changed lattice parameters to some extent. In detail, the NCM-5 exhibits a Ni:Co:Mn mole ratio close to 0.521:0.198: 0.281 , with higher nickel and lower manganese content compared with the proportion of 0.509:0.205:0.287 for NCM-P, which possibly arose from the different solubility of the metals in molten salts (Kimura, 2011). The micrographs of the obtained products are shown in Figure 3D,E, while both exhibit plate-like structures and no noticeable difference was observed from a morphological viewpoint.

To investigate the electrochemical properties of the obtained materials, NCM-P and NCM-5 were selected and compared using 2032 coin-type half cells with Li metal as the counter electrode. Figure $\mathbf{4 A}$ shows their rate capabilities under different currents of $0.5,1,3,5,7$, and $10 \mathrm{C}(\mathrm{C}=$ $165 \mathrm{~mA} \mathrm{~g}^{-1}$ ), and the detailed voltage profiles are also shown to compare. The NCM-5 can release an initial discharge capacity of $165.2 \mathrm{mAh} \mathrm{g}^{-1}$ under $0.5 \mathrm{C}$ within a potential range of $2.8-4.3 \mathrm{~V}$, which is compatible with the value of
167.5 $\mathrm{mAh}^{-1}$ released by NCM-P. Furthermore, both materials exhibit identical rate capabilities, as shown in Figure 4B, confirming the feasibility of using recycled molten salts in preparing layered materials. It is worth mentioning that the NCM-5 does show slight inferior rate capability, if not neglectable, compared with NCM-P, such as increasing the current from $0.5 \mathrm{C}$ to $1 \mathrm{C}$, a $95.5 \%$ against $96.5 \%$ capacity retention ratio can be kept for NCM-5, while up the current to $10 \mathrm{C}$, the capacity retention ratio is $76.2 \%$ for NCM-P, which is $74.9 \%$ for NCM-5.

The long-term cycling properties of both materials were also comparatively studied at 1C (Figure 4C). The obtained NCMs exhibit superior cycling stability, with above $75 \%$ capacity can be maintained after 500 cycles, very outstanding compared with their analogues with similar composition, (Gao et al., 2018; Zhao et al., 2018), highlighting the superiority of the molten salts assisted solid-state method, notice that these materials were untreated with any doping or coating strategies. However, slightly inferior cycling stability $(75.62 \%$ for NCM-5 against $78.37 \%$ for NCM-P) can be observed, which is similar to their rate capability performance.

The electrochemical impedance under OCP (open circuit potential) at the 5th and 500th cycles was further studied to evaluate the impedance change; results are shown in Figure 4D. In the fifth cycle, both cathodes exhibit similar charge-transfer resistance, $\mathrm{R}_{\mathrm{ct}}$. In contrast, after 500 cycles, the $\mathrm{R}_{\mathrm{ct}}$ increased 

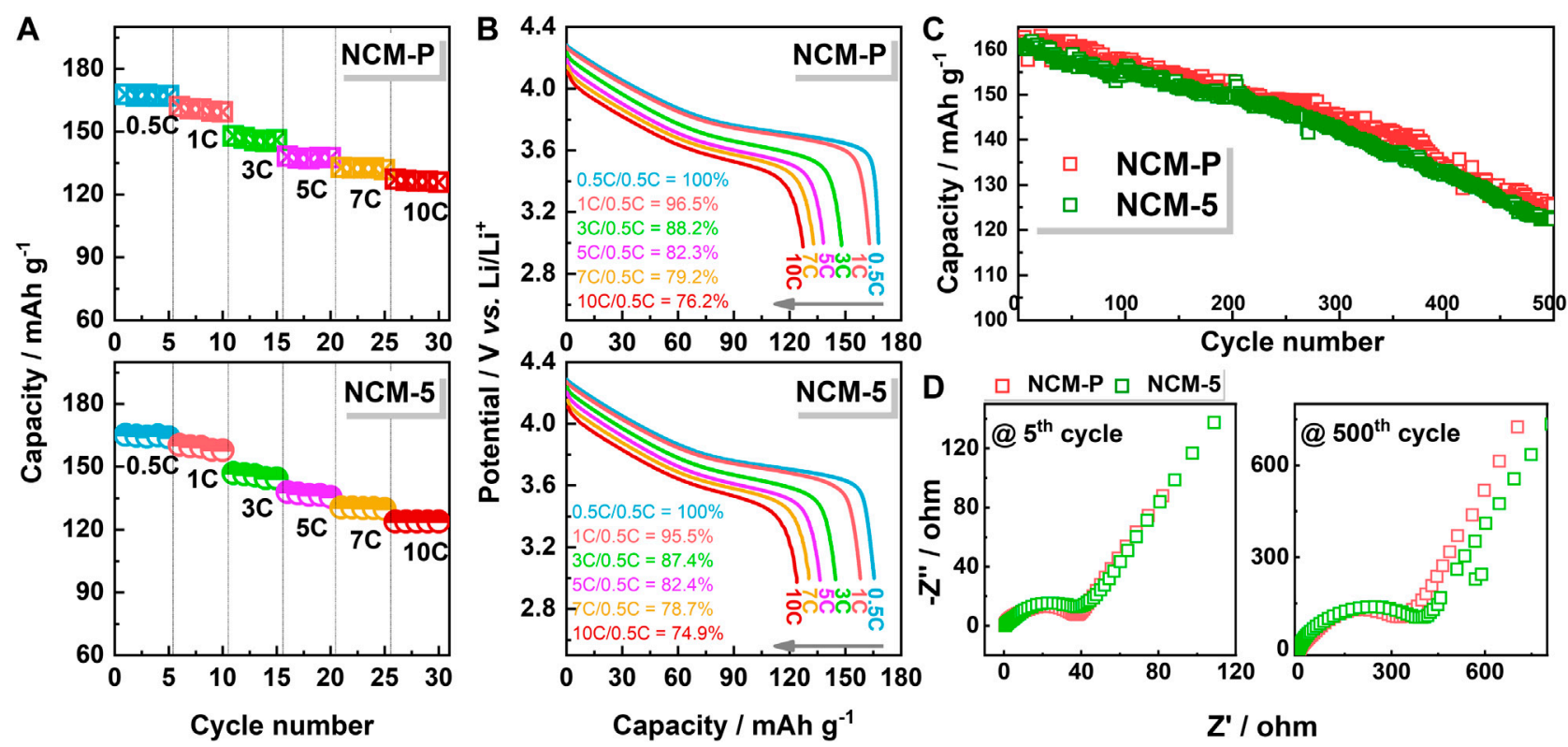

FIGURE 4 | (A) Rate capability, (B) detailed discharge profiles, (C) long-term cycling performance and (D) Nyquist plots for NCM-P and NCM-5.

rapidly for both materials, and a relatively more significant value is obtained for NCM-5, as indicated by the larger semicircle radius, consistent with its slight inferior electrochemical properties. Together, a possible reason for the decreased electrochemical property should be the higher $\mathrm{Ni}$ concentration in the material synthesized using recycled molten salts, which is more vulnerable to the electrolyte as the cycling proceeded (Kim et al., 2018). However, considering that the molten salts used in obtaining NCM-5 have already been cycled four times, the reported closed-loop utilization is still a promising method from an environmentally friendly viewpoint.

\section{CONCLUSION}

In conclusion, we have provided a simple, repeatable method to reuse the salt flux during molten-salt assisted solid-state synthesis in this study. With the quite outstanding performance of the obtained materials exhibited, the recycled salts are well-qualified in acting as a reaction medium during sintering. However, care must be taken that the recycled molten salts do introduce some negative effect because of the possibly metallic residues which exist in the molten salts, which will be studied in detail in our further work.

\section{REFERENCES}

Bianchini, M., Roca-Ayats, M., Hartmann, P., Brezesinski, T., and Janek, J. (2019). There and back again-the journey of LiNiO 2 as a cathode active material. Angew. Chem. Int. Ed. 58, 10434. doi:10.1002/anie.201812472

\section{DATA AVAILABILITY STATEMENT}

All datasets presented in this study are included in the article/ Supplementary Material.

\section{AUTHOR CONTRIBUTIONS}

The article was written through contributions of all authors. All authors have given approval to the final version of the manuscript.

\section{ACKNOWLEDGMENTS}

ZC wants to acknowledge the financial supports from National Natural Science Foundation of China (51602101), China Postdoctoral Science Foundation funded project (2019M652787), Planned Science and Technology Project of Hunan Province (2016TP1028), Hunan Provincial Education Office Foundation of China (No. 19A261), and the Construct Program of the Key Discipline in Hunan Province. RZ acknowledges the projects from Guangdong Science and Technology Department (2017A030310307, 2019A050513009) for financial supports.

Bianchini, M., Wang, J., Clément, R., Ouyang, B., Xiao, P., Kitchaev, D., et al. (2020). The interplay between thermodynamics and kinetics in the solid-state synthesis of layered oxides. Nat. Mater. 19, 1088-1095. doi:10.1038/s41563020-0688-6

Chang, Z., Chen, Z., Wu, F., Tang, H., Zhu, Z., Yuan, X., et al. (2008). Synthesis and properties of high tap-density cathode material for lithium ion battery by the 
eutectic molten-salt method. Solid State Ionics. 179, 2274. doi:10.1016/j.ssi. 2008.08.011

Dahn, J., Sacken, U., and Michal, C. (1990). Structure and electrochemistry of $\mathrm{Li} 1 \pm y \mathrm{NiO} 2$ and a new $\mathrm{Li} 2 \mathrm{NiO} 2$ phase with the $\mathrm{Ni}(\mathrm{OH}) 2$ structure. Solid State Ionics. 44, 87. doi:10.1016/0167-2738(90)90049-w

FTsalt-fact salt phase diagrams, http://www.crct.polymtl.ca/fact/phase_diagram. php?file=LiCl-LiOH.jpg\&dir=FTsalt, (Accessed: June 2020)

Gao, T.-P., Wong, K. W., Fung, K. Y., Zhang, W., and Ng, K. M. (2018). A rational three-step calcination strategy for synthesizing high-quality LiNi0.5Mn0.3 $\mathrm{Co} 0.2 \mathrm{O} 2$ cathode materials: the key role of suppressing Li2O formation. Electrochimica Acta. 288, 153. doi:10.1016/j.electacta.2018.09.012

He, B., Li, W.-C., and Lu, A.-H. (2015). High nitrogen-content carbon nanosheets formed using the Schiff-base reaction in a molten salt medium as efficient anode materials for lithium-ion batteries. J. Mater. Chem. A 3, 579. doi:10.1039/c4ta05056h

Hood, Z. D., Wang, H., Samuthira Pandian, A., Keum, J. K., and Liang, C. (2016). $\mathrm{Li} 2 \mathrm{OHCl}$ crystalline electrolyte for stable metallic lithium anodes. J. Am. Chem. Soc. 138, 1768. doi:10.1021/jacs.5b11851

Jr, G., Belharouak, I., Deng, H., Sun, Y., and Amine, K. (2011). Composition-tailored synthesis of gradient transition metal precursor particles for lithium-ion battery cathode materials. Chem. Mater. 23 (7), 1954. doi:10.1021/cm200058c

Kim, J., Lee, H., Cha, H., Yoon, M., Park, M., and Cho, J. (2018). Prospect and reality of Ni-rich cathode for commercialization. Adv. Energy Mater. 8, 1702028. doi:10.1002/aenm.201702028

Kimura, T. (2011). "Molten salt synthesis of ceramic powders," in Advances in ceramics-synthesis and characterization, processing and specific applications. Editor C. Sikalidis, London, United Kingdom: InTech, pp. 75-100.

Kudo, H. (1979). The rates of thermal decomposition of $\operatorname{LiOH}(\mathrm{s}), \operatorname{LiOD}(\mathrm{s})$ and LiOT(s). J. Nuc. Mater. 87, 185. doi:10.1016/0022-3115(79)90137-5

Li, J., Cameron, A. R., Li, H., Glazier, S., Xiong, D., Chatzidakis, M., et al. (2017). Comparison of single crystal and polycrystalline LiNi0.5Mn0.3Co0.2O2Positive electrode materials for high voltage li-ion cells. J. Electrochem. Soc. 164, A1534. doi:10.1149/2.0401714jes

Lee, W., Muhammad, S., Sergey, C., Lee, H., Yoon, J., Kang, Y., et al. (2019). Advances in the cathode materials for lithium rechargeable batteries. Angew. Chem. Int. Ed. 58, 2. doi:10.1002/anie.201902359

Liu, Y., Shen, Q., Zhao, X., Zhang, J., Liu, X., Wang, T., et al. (2020). Hierarchical engineering of porous $\mathrm{P} 2-\mathrm{Na} 2 / 3 \mathrm{Ni} 1 / 3 \mathrm{Mn} 2 / 3 \mathrm{O} 2$ nanofibers assembled by nanoparticles enables superior sodium-ion storage cathodes. Adv. Funct. Mater. 30, 1907837. doi:10.1002/adfm.201907837

Moorhous, S., Wu, Y., Buckley, H., and O'Hare, D. (2016). Time-resolved in-situ powder X-ray diffraction reveals the mechanisms of molten salt synthesis. Chem. Commun. 52, 13865. doi:10.1039/C6CC08133A
Ohzuku, T., Ueda, A., and Nagayama, M. (1993). Electrochemistry and structural chemistry of $\mathrm{LiNiO} 2(\mathrm{R} 3 \mathrm{~m})$ for 4 volt secondary lithium cells. J. Electrochem. Soc. 140, 1862. doi:10.1149/1.2220730

Sari, H., and Li, X. (2019). Controllable cathode-electrolyte interface of $\mathrm{Li}$ $\left[\mathrm{Ni}_{0.8} \mathrm{Co}_{0.1} \mathrm{Mn}_{0.1}\right] \mathrm{O}_{2}$ for lithium ion batteries: a review. Adv. Energy Mater. 9, 1901597.

Wang, L., Chen, B., Ma, J., Cui, G., and Chen, L. (2018). Reviving lithium cobalt oxide-based lithium secondary batteries-toward a higher energy density. Chem. Soc. Rev. 47, 6505. doi:10.1039/c8cs00322j

Wang, Z., Li, B., Ma, J., and Xia, D. (2014). Molten salt synthesis and highperformance of nanocrystalline Li-rich cathode materials. RSC Adv. 4, 15825. doi:10.1039/c4ra06386d

Xu, Q., Li, X., Kheimeh Sari, H. M., Li, W., Liu, W., Hao, Y., et al. (2020). Surface engineering of $\mathrm{LiNi} 0.8 \mathrm{Mn} 0.1 \mathrm{Co} 0.1 \mathrm{O} 2$ towards boosting lithium storage: Bimetallic oxides versus monometallic oxides, Nano Energy. 77, 105034. doi:10.1016/j.nanoen.2020.105034

Zhao, R., Miao, J., Wu, Z., Hung, I., Lv, D., Zeng, R., et al. (2018). Synthesis of layered materials by ultrasonic/microwave-assisted coprecipitation method: a case study of $\mathrm{LiNi}_{0.5} \mathrm{Co}_{0.2} \mathrm{Mn}_{0.3} \mathrm{O}_{2}$. Sustain. Mater. Tec. 18, e00083. doi:10.1016/ j.susmat.2018.e00083

Zhao, R., Zhang, J., Lee, G.-H., Zhang, K., Lau, V. W.-h., Lee, J.-J., et al. (2020). The origin of heavy element doping to relieve the lattice thermal vibration of layered materials for high energy density Li ion cathodes. J. Mater. Chem. A 8, 12424. doi:10.1039/d0ta03979a

Zhu, J., and Chen, G. (2019). Single-crystal based studies for correlating the properties and high-voltage performance of $\mathrm{Li}[\mathrm{NixMnyCo} 1-\mathrm{x}-\mathrm{y}] \mathrm{O} 2$ cathodes. J. Mater. Chem. A 7, 5463. doi:10.1039/c8ta10329a

Conflict of Interest: HY was employed by Guangdong Brunp Recycling Technology Co., Ltd.

The remaining authors declare that the research was conducted in the absence of any commercial or financial relationships that could be construed as a potential conflict of interest.

Copyright $\odot 2021$ Chen, Wang, Yu, Guo, Zhong, Hu, Zhao and Chen. This is an open-access article distributed under the terms of the Creative Commons Attribution License (CC BY). The use, distribution or reproduction in other forums is permitted, provided the original author(s) and the copyright owner(s) are credited and that the original publication in this journal is cited, in accordance with accepted academic practice. No use, distribution or reproduction is permitted which does not comply with these terms. 